\title{
Selection of the Most Suitable Statistical Process Control Approach for Short Production Runs: A Decision-Model
}

\author{
Pedro A. Marques, Carlos B. Cardeira, Paula Paranhos, Sousa Ribeiro, and Helena Gouveia
}

\begin{abstract}
Nowadays, customers are increasingly claiming not only for better quality products at the lowest possible cost, but also demanding customized solutions to satisfy their specific, sometimes unique, needs and wants. Due to this, manufacturing companies are seeking to adopt higher agile production models, such as mass customization strategies. In the quality control field, statistical process control (SPC) methods have been widely used to monitor process performance and detect abnormal situations in its behavior; however, traditional SPC approaches are usually not appropriate for small lot or batch sizes, for the start-up of a process, and for situations where a high variety of mixed products exist. Such situations are within the scope of the so called short production runs. Several SPC schemes have been proposed for short-run environments; all of them have their own advantages, shortcomings, and more suitable for certain production scenarios. This paper provides an up-to-date literature review on the topic, identifies classes of SPC short-run methods, and presents a decision-model that guides production managers in the choice of the most appropriate SPC short-run approach. The model was validated in a textile production company, and is being incorporated into a software package.
\end{abstract}

Index Terms-Decision-model, short-run, statistical process control (SPC).

\section{INTRODUCTION}

The goal of statistical process control (SPC) is to make a process stable or predictable, by distinguishing common variation from special/sporadic variation. Capability analysis and process improvement actions shall only be put in place if the observable variability of the process is absent of special

Manuscript received February 5, 2014; revised April 17, 2014. This work is part of the Project Produtech PSI - New Products and Services for the Manufacturing Industry. It has been partly funded by the Incentive System for Technology Research and Development in Companies (SI I\&DT), under the Competitive Factors Thematic Operational Program of the Portuguese National Strategic Reference Framework, and EU's European Regional Development Fund. The authors also wish to acknowledge the gratitude and appreciation to the PPS3-Produtech PSI project partners involved in activities 3.4 and 3.6 for their contribution. The authors would also like to thank the work and involvement of Sérgio Fernandes of SisTrade.

P. A. Marques is with the Department of Strategy and Special Projects, ISQ - Instituto de Soldadura e Qualidade, Av. Prof. Dr. Cavaco Silva, 33, Taguspark, 2740-120 Porto Salvo, Portugal (e-mail: pamarques@ isq.pt).

C. B. Cardeira is with the Department of Mechanical Engineering (IDMEC), Instituto Superior Técnico (IST), University of Lisbon, 1049-001 Lisboa, Portugal (e-mail: carlos.cardeira@tecnico.ulisboa.pt).

P. Paranhos is with IDEPA - Ind. Passamanarias, Lda., Av. 1. de Maio, 71, 3700-227 S. João Madeira, Portugal (e-mail: paula.paranhos@idepa.com)

S. Ribeiro is with SisTrade - Software Consulting, R. Manuel Pinto de Azevedo, 64B, 4100-320 Porto, Portugal (e-mail: sousa.ribeiro@sistrade.com).

H. Gouveia is with the Lab I\&D, ISQ - Instituto de Soldadura e Qualidade, Av. Prof. Dr. Cavaco Silva, 33, Taguspark, 2740-120 Porto Salvo, Portugal (e-mail: hngouveia@isq.pt). causes of variation. Conventional SPC methods often do not work well in short-run situations, such as in the following:

1) Job shop processes where a high diversity of custom or semi-custom parts are manufactured. Monitoring such high variety of products would require a large number of control charts, which is unpractical in most situations.

2) Just-in-time (JIT) systems where low levels of inventory are required, thus demanding the manufacturing of smaller quantities of parts in shorter production runs.

3) Start-up of a process or initiation of a new process, where insufficient number of subgroups is available, so the parameters of the process cannot be accurately estimated.

As underlined in [1], [2], in order to manage these situations, various SPC short-run methods have been proposed in the literature. Several distinct approaches to monitor a short-run production process based on statistical principles do exist, with their own strengths and drawbacks. The selection of the best method in a short production run is rarely straightforward, because it relies on a set of important criteria and decision-made points; due to this, a new decision-model that enables a systematic selection of the best SPC method for different short-run manufacturing realities is herein proposed.

This paper is organized in six sections. Section II contains a careful literature review on SPC for short-run situations, where the different approaches that have been suggested on the topic are discussed, compared, and classified according to their purpose. Based on such classification, Section III then presents the decision-model, its reasoning and it how it can be used by decision-makers to select the short-run SPC approach that best suits the nature and characteristics of the process to be controlled. Section IV illustrates the applicability of the model in a real factory environment, by showing how it was used to select the most suitable short-run SPC method. This section also discusses how the decision-model is being integrated into a software solution. Finally, the main conclusions of this paper are summarized in Section V.

\section{SPC FOR SHORT PRODUCTION RUNS - LITERATURE REVIEW}

Traditional control charts assume that data for estimating the process parameters are available during a production run [3]. However, many modern manufacturing systems do not satisfy these assumptions [4] due to the low-volume of parts produced and/or to a high variety of mixed products. Short-run processes imply the high frequency of process setups [5]. The following examples can be considered as short-run: 
- At the start-up stages of a production process, where little or no historical data is available [6].

- In job shop manufacturing processes, characterized by producing small quantities of a large variety of parts [7].

- In repetitive production industries where frequent setup changes occur [8] to accommodate different product types.

- When the rate of production and/or inspection can impose constraints in the number of samples to be inspected [9].

- In low-volume production processes motivated by the adoption of JIT systems [10].

Numerous works on the use of short runs SPC procedures have been suggested to date. In this section, a careful literature review in order to identify, compare and classify the different existing approaches on the subject is performed.

Hillier [11] was one of the first researchers to suggest solutions to use SPC in short-run cases, by developing a two-stage short-run theory for $X$-bar and $R$ control charts, where $X$-bar and $R$ are the mean and the range of a subgroup, respectively. Due to the lack of available data that is inherent to a short-run situation, the probability of a false alarm is exceedingly high when estimating the process parameters; for this reason, Hillier derived equations to adjust the standard control limits used in $X$-bar and $R$ control charts, for both stages I and II. In stage I, $m$ subgroups of size $n$ are drawn to retrospectively determine in the control charts whether the process was stable or not; stage II only starts when the process is under control and is intended to monitor the future behavior of the process. Yang and Hillier [12] extended the two-stage reasoning by deriving equations to calculate the control limits for the $(X$-bar, $v)$ and $(X$-bar, $\sqrt{v})$ charts, where $v$ is the variance of a subgroup. Elam and Case generalized and improved the two-stage theory; in their works referenced in [13]-[15], they address the problem of limited tabulated values for the control chart factors provided in [11], [12], by introducing computer programs to determine the chart factors more accurately. They also describe in detail the two-stage approach for the following control chart pairs: $X$-bar and $v$ charts [16]; $X$-bar and $\sqrt{v}$ charts [16]; $X$-bar and $s$ charts (where $s$ is the standard-deviation) [17]; $X$-bar and $M R$ charts [18]. According to [18], the $(X$-bar, $s)$ and $(X-b a r, \sqrt{v})$ charts are similar, but the latter are more difficult to implement.

A limitation of the two-stage procedures is that they require the availability of some amount of historical data to estimate the process parameters. To address this problem, Quesenberry proposed a set of short-run control charts, called Q-charts [19], which are intended to detect changes in the process parameters during the initiation of a process, since they do not require rich preliminary data [3]. The basic idea behind Q-charts is to construct a Q-statistics, by using a certain transformation, so data can be considered independent and identically distributed (i.i.d.) with known probability distribution when the process is in control [20]. Such transformations are explained in [19] for the case of continuous variables and in [21], [22] for attribute variables. The detection capability of a Q-chart is negatively affected when a mean shift occurs in the early phases of the charting [3]. To minimize this problem, Del Castillo and Montgomery [7] suggested modifications in the original Q-charts to enhance their statistical properties, by proposing the following two alternative approaches, which are valid when the process mean is considered known and the standard-deviation is assumed as unknown:

1) An Exponentially Weighted Moving Average (EWMA) method, which is preferable when it is desirable to detect small shifts in the parameters of the process.

2) An adaptive Kalman filtering method, which is also useful when the process mean cannot be considered known.

AdaptiveQ-charts that enable variable sample sizes and/or sampling intervals are discussed in [23], [24]. Kawamura et al. [25] used the Q-statistics for autocorrelated data cases.

Q-charts are the most well-known and popular self-starting scheme to monitor a process in short production runs. A self-starting procedure permits real-time charting that can begin with the second sample, while the process parameters estimates are updated with each new observation. Other self-starting approaches have been proposed. Hawkins [26] introduced a self-starting CUSUM chart for detecting small shifts in both the location and dispersion parameters; Koning and Does [27] suggested a CUSUM chart for individual observations, to detect linear trends; Capizzi and Masarotto [6] presented a charting scheme able to detect small shifts in the process mean at the very beginning of a production run.

An advantage of a Q-chart is that it enables the monitoring of many quality characteristics, eventually corresponding to different products, in a single chart. The use of a Q-chart in a product variety situation is appropriate when the variances of the different quality characteristics are unknown; when it is not the case, it is preferable to select a Deviation chart [28] or a Z-chart [29]; the former shall only be used when the variances of the different characteristics are not significantly different from each other.

A recent SPC short-run approach also adopts a data transformation, where a T-statistic is obtained, which enables the drawing of a set of control charts, known as t-charts. These charts, intended to monitor the process mean were first proposed by Zhang et al. [30], by presenting an $X$-bar t-chart and a EWMA t-chart. The applicability of these two charts to short production runs was described by Celano et al. [9], who also studied their statistical properties. A t-chart does not require a preliminary estimation of the in-control process standard-deviation, so it also can be used to monitor the start-up of a process. However, t-charts assume that at the beginning of a production run, the in-control mean is perfectly set up on the process target, or that the initial setup error, shifting the mean away from the target, is known $a$ priori [31]. Gu et al. [4] showed how t-charts can be successfully implemented in a multi-variety production run. Calzada and Scariano [32] introduced synthetic versions of the $X$-bar and EWMA t-charts to improve their statistical properties. Castagliola et al. [31] proposed an adaptive $X$-bar $\mathrm{t}$-chart that permits the adoption of a variable sample size strategy.

Change-point methods form another relevant class of approaches to deal with short-run situations for when both location and dispersion process parameters are unknown. They can detect persistent shifts in the values of the process location and/or dispersion parameters. Hawkins et al. [33] formulated a change-point model to monitor the process 
mean, and Hawkins and Zamba [34] proposed a formulation to detect shifts in the process variance. The generalization of the change-point model to monitor both the in-control mean and the variance of a process is explained in [35].

Short-run SPC methods were also proposed for cases of multivariate and autocorrelated data. Zamba and Hawkins [36] extended the change-point model for multivariate data by presenting a model to monitor the mean vector (parameter of location) and/or the covariance structure (parameter of dispersion) of a process; Khoo and Gan [37] introduced a multivariate CUSUM chart for individual measurements that enables the control of both the mean vector and the covariance; Jaupi et al. [38] described a multivariate control chart for subgroups to monitor the mean vector and of the covariance; Makis [39] suggested a multivariate EWMA chart to control the mean vector in finite production runs using the Bayesian statistics. Snoussi [40] proposed a multivariate control chart for processes with i.i.d data (i.e. autocorrelated). Other SPC short-run approaches for autocorrelated data, using control charts were suggested by Snoussi et al. [41] and Snoussi and Limam [42]. Non-charting procedures for autocorrelated data have also been described: Wright et al. [43] recommended a joint-estimation method to detect four different types of special causes of variation in the process mean; $\mathrm{Wu}$ and $\mathrm{Yu}$ [44] presented a neural network model to detect and classify types of shifts in the mean and/or variance of a process; Tsiamyrtzis and Wright [45] came up with a Bayesian EWMA procedure to detect shifts in the parameter of location in the early phases of a process start-up.

To deal with non-Normal data in short-run processes, Zhou et al. [46] developed a nonparametric control chart inspired in the change-point model to control the parameter of location. Zou and Tsung [47] provided a solution to monitor both the location and dispersion parameters of a short-run process by employing a likelihood ratio-based distribution-free method.

TABLE I: CLASSIFICATION OF THE SPC SHORT-RUN APPROACHES

\begin{tabular}{|c|c|}
\hline Category & Description of the approach class \\
\hline $\begin{array}{l}\text { Attribute data } \\
\text { short-run }\end{array}$ & $\begin{array}{l}\text { Applied to cases where data is not continuous, but } \\
\text { discrete. }\end{array}$ \\
\hline $\begin{array}{l}\text { Multivariate data } \\
\text { short-run }\end{array}$ & $\begin{array}{l}\text { Applied to cases where more than one quality } \\
\text { characteristic needs to be monitored simultaneously. }\end{array}$ \\
\hline $\begin{array}{l}\text { Autocorrelated data } \\
\text { short-run }\end{array}$ & $\begin{array}{l}\text { Applied to cases where data is not independent } \\
\text { neither identically distributed (i.i.d.). }\end{array}$ \\
\hline $\begin{array}{l}\text { Fuzzy data } \\
\text { methods }\end{array}$ & $\begin{array}{l}\text { Applied to cases when dealing with data that is not } \\
\text { exact (e.g. linguistic, scales, degrees of conformity). }\end{array}$ \\
\hline $\begin{array}{l}\text { Self-starting } \\
\text { methods }\end{array}$ & $\begin{array}{l}\text { Useful for process start-ups, it updates parameters' } \\
\text { estimates with new observations. }\end{array}$ \\
\hline t-charts & $\begin{array}{l}\text { Enable the monitoring of the parameter of location; } \\
\text { assume that the in-control mean is perfectly set up on } \\
\text { the target, or that the initial setup error is known. }\end{array}$ \\
\hline $\begin{array}{l}\text { Change-point } \\
\text { methods }\end{array}$ & $\begin{array}{l}\text { This type of methods is advantageous when aiming to } \\
\text { detect persistent shifts in the process parameters. }\end{array}$ \\
\hline $\begin{array}{l}\text { Two-phase } \\
\text { methods }\end{array}$ & $\begin{array}{l}\text { Useful when the process parameters can be estimated } \\
\text { in the first phase, by using modified control limits. }\end{array}$ \\
\hline $\begin{array}{l}\text { Methods for } \\
\text { product variety }\end{array}$ & $\begin{array}{l}\text { Applied when the process parameters are known and } \\
\text { data from different quality characteristics of one or } \\
\text { more products is to be plotted in a single chart. }\end{array}$ \\
\hline Other approaches & $\begin{array}{l}\text { Grey predictive charts, neural network models, and } \\
\text { specific Bayesian univariate charts are here included. }\end{array}$ \\
\hline
\end{tabular}

Several other methodologies for short-run contexts were developed to monitor continuous variables. Guo and Dunne
[48] presented three short-run control methods based on the grey differential equation theory: 1) Grey predictive Shewhart control chart; 2) Grey predictive CUSUM control chart, useful to detect small shifts in the process mean values; 3) Grey fuzzy predictive control scheme, when the requirements for quality conformance are vague or imprecise. The grey predictive approach only enables the monitoring of the process mean, and its main advantage is that it enables out-of-control pattern recognition. Aminnayeri et al. [49] developed a control chart method based on non-conformity degree, ruled by the use of fuzzy membership function.

Short-run SPC procedures have also been developed for attribute data, being divided into two classes: control charts for proportions of defectives and charts for counts of defects. For proportions, most of the methods are modifications of the $p$-chart to control the ratio of nonconforming items.

TABLE II: ALLOCATION OF DIFFERENT SPC SHORT-RUN METHODS IN THEIR CORRESPONDING CLASS OF APPROACHES

\begin{tabular}{|c|c|c|}
\hline Category & Method name(s) & Ref. \\
\hline \multirow{6}{*}{$\begin{array}{l}\text { Attribute data } \\
\text { short-run }\end{array}$} & Binomial Q-chart & {$[50]$} \\
\hline & $\begin{array}{l}\text { Geometric Q-chart; specially designed CUSUMQ } \\
\text { and EWMAQ charts for proportions }\end{array}$ & [51] \\
\hline & Short-run $\alpha$-cut $p$-control chart & {$[52]$} \\
\hline & $\begin{array}{l}\mathrm{Q} u \text { and } \mathrm{Q} c \text { charts; specially designed CUSUMQ } \\
\text { and EWMAQ charts for counts }\end{array}$ & [53] \\
\hline & $p$-chart for small number of subgroups & [54] \\
\hline & $\mathrm{Zu}, \mathrm{Z} c$, and $\mathrm{Zp}$ control charts & [28] \\
\hline \multirow{7}{*}{$\begin{array}{l}\text { Multivariate } \\
\text { data short-run }\end{array}$} & Spatial rank-based multivariate EWMA chart & {$[20]$} \\
\hline & Control chart based on the influence function & [38] \\
\hline & $\begin{array}{l}\text { Multivariate CUSUM chart for individual } \\
\text { observations using V statistic }\end{array}$ & [37] \\
\hline & Multivariate short-run Snapshot Q chart & [55] \\
\hline & Multivariate Bayesian for finite production run & [39] \\
\hline & Multivariate chart for process mean (V statistic) & {$[56]$} \\
\hline & Multivariate change-point model & [36] \\
\hline \multirow{6}{*}{$\begin{array}{l}\text { Autocorrelated } \\
\text { data short-run }\end{array}$} & Bayesian EWMA method & [45] \\
\hline & Joint Estimation (JE) method & [43] \\
\hline & SCC Q-charts; EWMA Q-charts & [41] \\
\hline & Adaptive filtering method & [57] \\
\hline & Joint Estimation method (extended for $n>1$ ) & [58] \\
\hline & Change-point model formulation (UU case) & [42] \\
\hline $\begin{array}{l}\text { Fuzzy data } \\
\text { methods }\end{array}$ & Non-conformity degree fuzzy control chart & [49] \\
\hline \multirow{6}{*}{$\begin{array}{l}\text { Self-starting } \\
\text { methods }\end{array}$} & $\mathrm{Q}($ Xbar $), \mathrm{Q}(R), \mathrm{Q}\left(\mathrm{s}^{2}\right)$, and $\mathrm{Q}(M R)$ charts & [19] \\
\hline & EWMAQ and CUSUMQ charts & [59] \\
\hline & Self-starting CUSUM chart for mean and scale & [26] \\
\hline & Case III EWMA chart; Adaptive Kalman filtering & [7] \\
\hline & $\mathrm{Q}_{\mathrm{I}}$ and $\mathrm{Q}_{\mathrm{II}}$ charts & [3] \\
\hline & Adaptive CUSUM of Q chart & [24] \\
\hline \multirow[t]{3}{*}{ t-charts } & Xbar and EWMA t-chart & [9] \\
\hline & syn-t and synEWMA t-chart & [32] \\
\hline & VSS t-chart & [31] \\
\hline \multirow{4}{*}{$\begin{array}{l}\text { Change-point } \\
\text { methods }\end{array}$} & Change-point model for shift in the mean & [33] \\
\hline & Change-point model for shift in the variance & [34] \\
\hline & Change-point model (mean and variance) & [35] \\
\hline & Nonparametric chart based on change-point model & [46] \\
\hline \multirow{4}{*}{$\begin{array}{l}\text { Two-phase } \\
\text { methods }\end{array}$} & Two-stage short run $(X b a r, R)$ control charts & [11] \\
\hline & Two stage $(X-b a r, v)$ and $(X-b a r, \sqrt{v})$ charts & [12] \\
\hline & Two-stage $(X b a r, s)$ charts & [17] \\
\hline & Two-stage $(X, M R)$ charts & [18] \\
\hline \multirow{3}{*}{$\begin{array}{l}\text { Methods for } \\
\text { product variety }\end{array}$} & Deviation charts & [28] \\
\hline & Z/W charts & [29] \\
\hline & $\delta$ charts for short-runs & {$[60]$} \\
\hline \multirow{2}{*}{$\begin{array}{l}\text { Other } \\
\text { approaches }\end{array}$} & Grey predictive charts & [48] \\
\hline & Neural network control for start-up processes & [61] \\
\hline
\end{tabular}

Quesenberry [50] proposed a binomial Q-chart to detect 
moderate or large shifts in the proportion of defectives, whereas for detecting small shift sizes the author suggested specially designed CUSUM and EWMA Q-charts [51]. A geometric Q-chart, which is particularly useful to monitor high quality short-run processes, was also proposed in [51]; thus, geometric Q-charts are recommended when the required value for the parameter $p$ is very small. When $p$ is known $a$ priori, Q-charts are not the best option, being preferable to make use the $Z_{p}$ chart suggested by Bothe [28]. For ambiguous or imprecise data, Fonseca et al. [52] presented a fuzzy $\alpha$-cut $p$-chart. For counts, when the process parameter cannot be estimated a priori, Bothe [28] proposed a $\mathrm{Z}_{c}$ chart for monitoring the total number of defects (parameter $c$ ), and a $Z_{u}$ chart to control the number of defects per unit (parameter $u$ ). If the process parameter is unknown, the $\mathrm{Q}_{c}$ (for the parameter $c$ ) or $\mathrm{Q}_{u}$ (for the parameter $u$ ) charts are preferable.

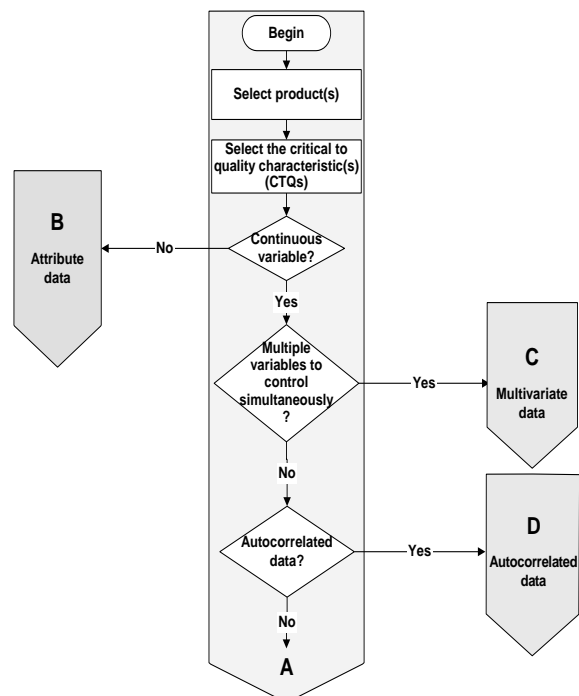

Fig. 1. General framework of the decision-model.

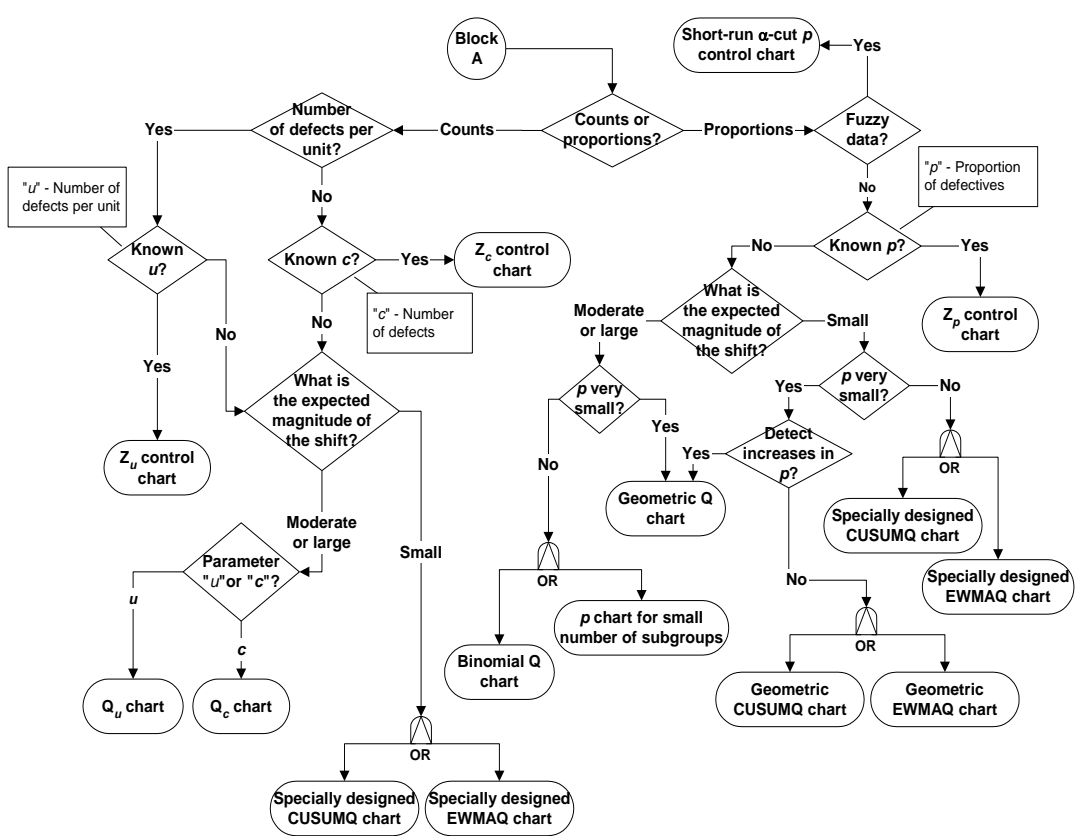

Fig. 2. Flowchart of block B of the decision-model concerning SPC short-run methods for attribute data.

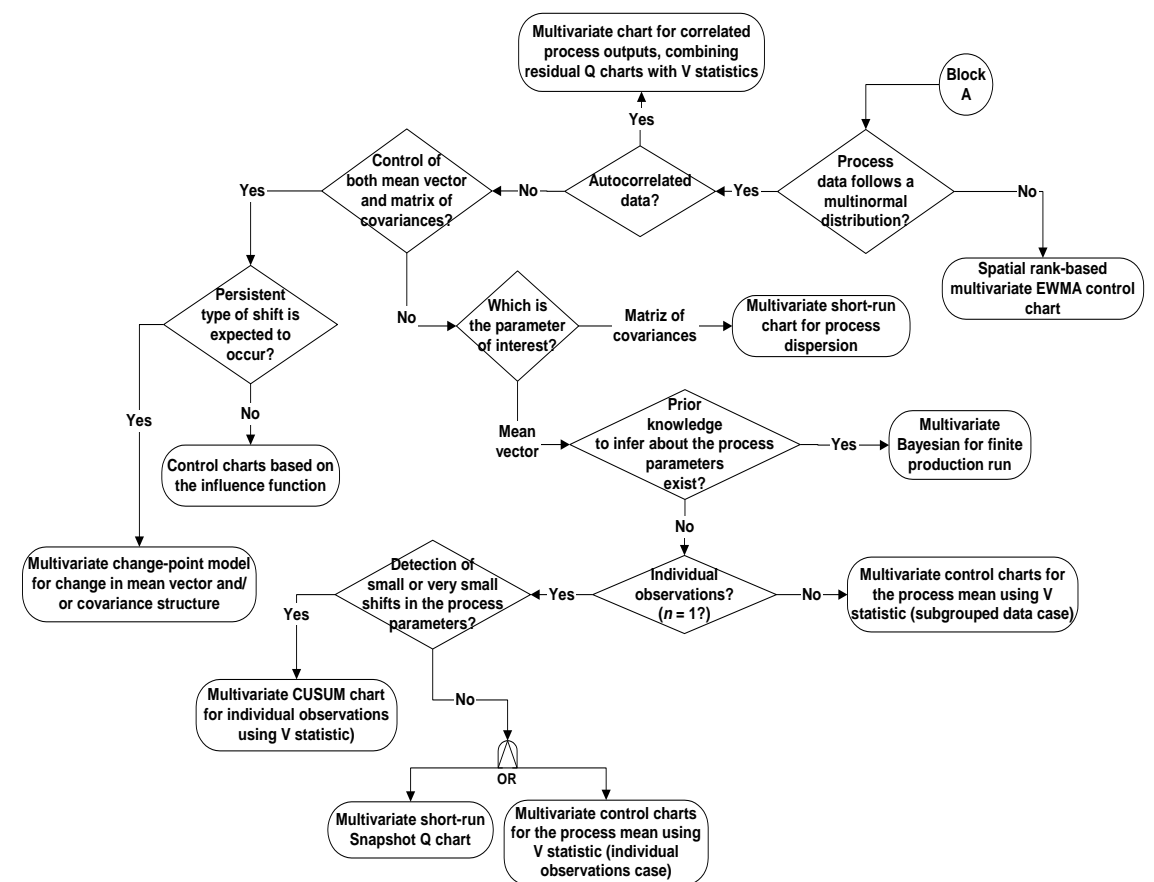

Fig. 3. Flowchart of block $\mathrm{C}$ of the decision-model concerning SPC short-run methods for multivariate data. 


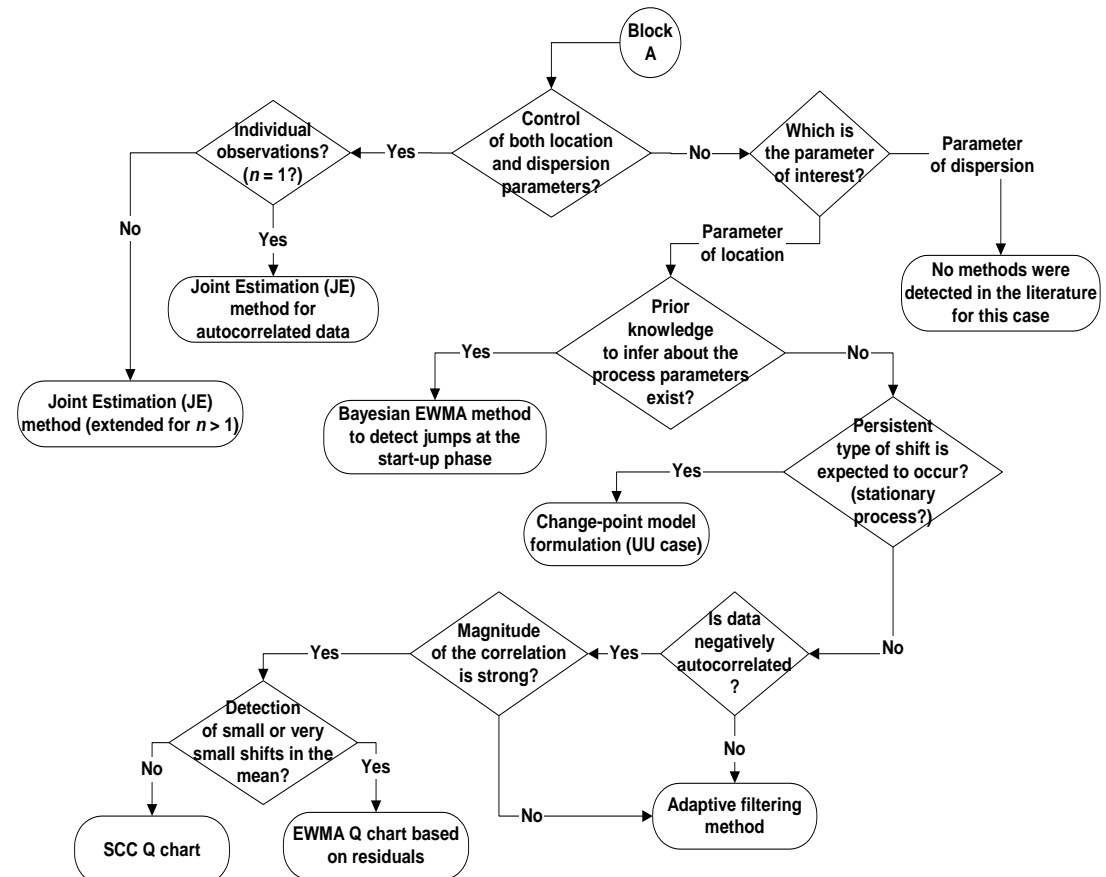

Fig. 4. Flowchart of block D of the decision-model concerning SPC short-run methods for autocorrelated data.

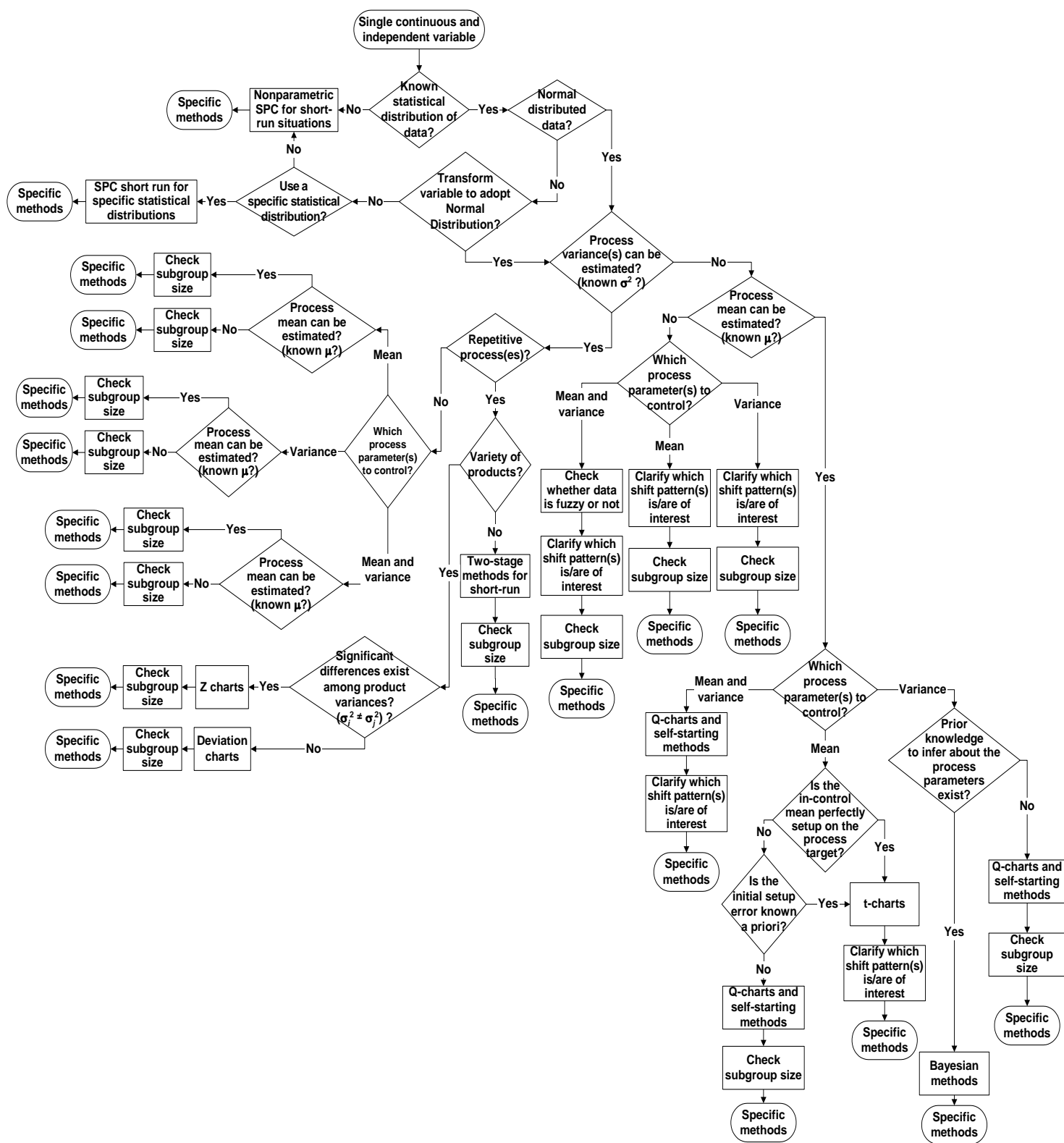

Fig. 5. High-level view of the flowchart corresponding to block A of the decision-model. 
Table I organizes several of the existing approaches into a set of ten categories of SPC short-run methods. In Table II, a wide range of specific methods proposed in the literature are scoped in each of those 10 categories. To the exception of the first category mentioned on Table I and Table II, all the others concern the control of continuous variables.

Some of the methods depicted in Table II could actually be scoped in more than one category. For instance, the method suggested in [36] that was included in the "multivariate data short-run" category, uses a change-point formulation. The reasoning behind the categorization established in Table I and Table II is embedded in the decision-model in the Section III.

The literature review also revealed a lack of existing publications with methodologies or frameworks that provides systematic guidelines and/or criteria towards the selection of the most appropriate short-run SPC procedure. In this matter, the work carried out by Requeijo [62] should be highlighted, since the author develops a helpful flowchart that establishes a logical path that permits a decision-maker to choose the best SPC approach, including in short-run cases; however, the author did not include relevant SPC short-run approaches, such as two-phase models, change-point models, and t-charts.

\section{DECISION-MODEL}

The review of the relevant literature was the starting point to conceive the decision-model presented in this paper, which importance is justified by the following:

- The relevance of the quality control procedures for monitoring short-run processes is increasingly growing.

- The high-diversity of SPC short-run methods is likely to create confusion when one needs to decide which specific procedure to adopt if no objective criteria are available.

- As long as the authors are aware, no decision-model to select the best SPC short-run method was ever proposed.

The main goal for developing the decision-model was to provide a tool that could help any industry to determine which SPC short-run method would be most appropriate given the characteristics of their manufacturing processes.

Fig. 1 depicts the general framework of the model, which comprises four blocks of flowcharts. The flowcharts contained in each block B, C, D and A are detailed in Fig. 2-Fig. 5, respectively. The flowchart contained in block A guides in the choice of the most suitable SPC short-run procedure under the scope of the remaining classes of methods indicated in Table I and Table II. As Fig. 1 depicts, the decision-model was designed in a way that blocks B, C, and $\mathrm{D}$ derive from block $\mathrm{A}$.

Fig. 2-Fig. 4 show the flowcharts inherent to the decision-model for the cases of attribute (block B), multivariate (block C), and autocorrelated (block D) data, respectively. Due to its length, the whole detail of the flowchart in block A cannot be shown, so Fig. 5 only depicts the reasoning and the main criteria that govern the decision-making process in this block.

\section{CASE StUdy}

The decision-model described in the previous section was tested in IDEPA, a textile industrial company, founded in 1965 , which main activity is the manufacture of woven labels and ribbons. Its manufacturing process, which high-level mapping is showed in Fig. 6, is characterized by the production of a high variety of items, generally done in small batches. The depicted process sequence is actually flexible, attending to the specificities of the customer requirements.

From collected data, it was concluded that most of the defects are originated in the weaving operation (Fig. 7), namely the following two: 1) lines/stripes in the tissue; 2) untied threads. Both correspond to characteristics that cannot be monitored through a continuous variable, so their control is based on attribute data that rely on visual inspection.

Thus, the preferable short-run procedure in the IDEPA case study is somewhere contained in block B; so, one needs to go through the flowchart contained in this block (Fig. 2).

IDEPA is interested in monitoring proportions of defectives resulting from the weaving operation; it means that the right side of the mentioned flowchart is the one that should be considered. The evaluation of the conformity of any produced item is not ambiguous and the decision of conformity is binary (i.e. defective or non-defective), so fuzzy data is not involved. Based on the cumulated experience, moderate to large shift in process parameters are expected to occur, in contrast with small shifts that are unlikely to happen.

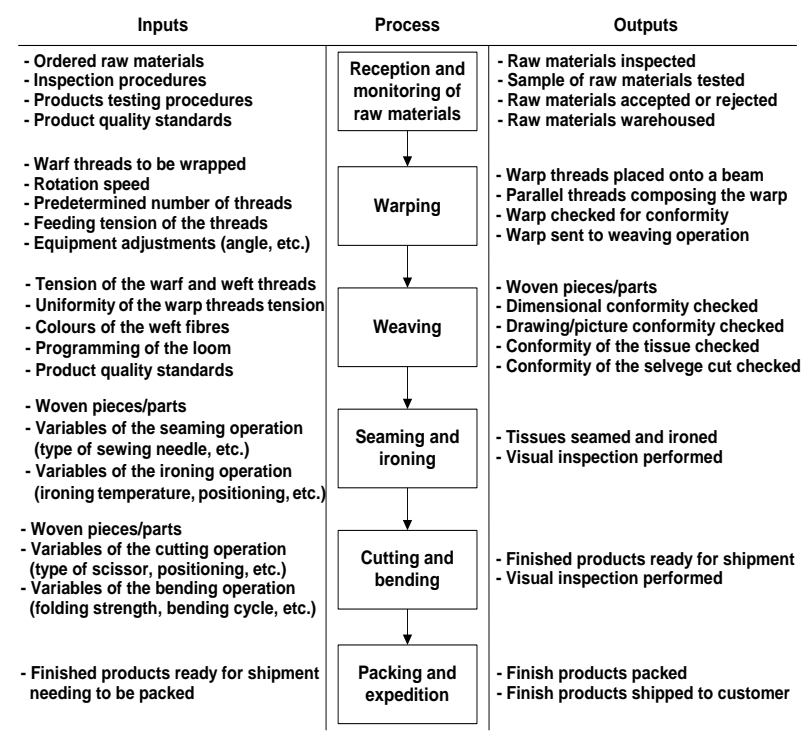

Fig. 6. High-level manufacturing process mapping of IDEPA.

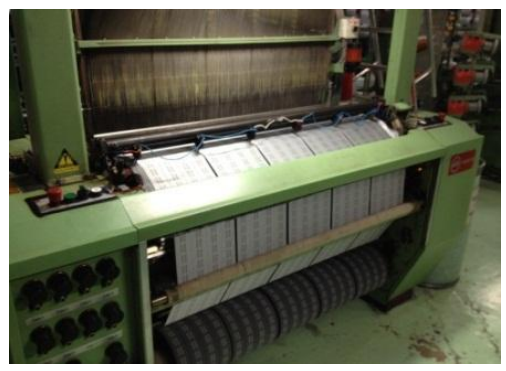

Fig. 7. Weaving loom at IDEPA.

Following the previous reasoning and since the proportion of defectives (parameter $p$ ) estimated using historical data is not very small, the flowchart depicted in Fig. 2 suggests two possible control charts for IDEPA: 1) Binomial Q-chart or; 2) 
p-chart for small number of subgroups. The first was proposed by Quesenberry [50], while the latter was suggested by Nedumaran and Leon [54].

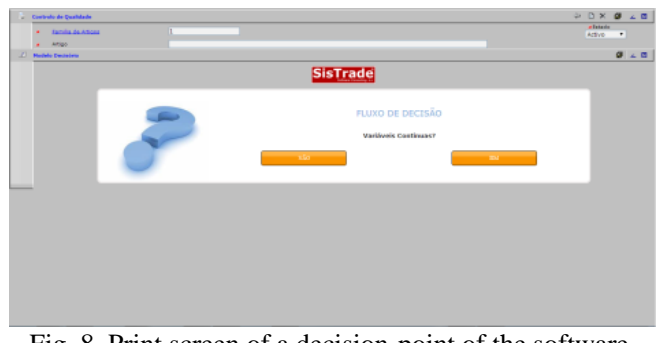

Fig. 8. Print screen of a decision-point of the software.

The decision-model is currently being incorporated into a software solution developed by SisTrade company (Fig. 8).

\section{Conclusions}

This paper introduces a novel decision-model to help managers to select the best SPC approach to monitor the critical to quality characteristics in any type of short-run production process. To validate the model, it was applied to the case of a manufacturing process of a textile company; however, despite the successful implementation, the usefulness and applicability of the model need to be further tested in other kinds of processes, in order to take additional conclusions about its effectiveness to other situations.

A critical foundation for developing this model was the literature review that was undertaken, and the identification of the different existing methods on SPC for short-run processes.

As future research work, in addition of testing the model in other short-run contexts, it is our intention to incorporate the model within the Six Sigma framework, so the control and improvement initiatives can be properly linked.

\section{REFERENCES}

[1] M. E. Elam, "Control charts for short production runs," Encyclopedia of Statistics in Quality and Reliability, March 2008.

[2] D. Noskievičová and B. Woska, "Design of methodology for application of statistical control on short run Processes in metallurgy," Metalurgija, vol. 53, pp. 81-84, January 2014.

[3] F. He, W. Jiang, and L. Shu, "Improved self-starting control charts for short runs," vol. 3, no. 3, pp. 289-308, September 2008.

[4] K. Gu, X. Jia, H. You, and S. Zhang "A t-chart for monitoring multi-variety and small batch production run," Quality and Reliability Engineering International, vol. 30, no. 2, pp. 287-299, 2014

[5] R. Pan, "Statistical process adjustment methods for quality control in short-run manufacturing," Ph.D. dissertation, Dept. Industrial and Manufacturing Engineering, Pennsylvania State University, PA, 2002.

[6] G. Capizzi and G. Masarotto, "An enhanced control chart for start-up processes and short runs," Quality Technology \& Quantitative Management, vol. 9, no. 2, pp. 189-202, June 2012.

[7] E. D. Castillo and D. C. Montgomery, "Short run statistical process control: Q-chart enhancements and alternative methods," Quality and Reliability Engineering International, vol. 10, no. 2, pp. 87-97, 1994.

[8] P. F. Tang, "Statistical process control with special reference to multivariate processes and short runs," Ph.D. thesis, Dept. Computer \& Mathematical Sciences, Victoria Univ. of Technology, Australia, 1996.

[9] G. Celano, P. Castagliola, E. Trovato, and S. Fichera, "Shewhart and EWMA t control charts for short production runs," Quality \& Reliability Engineering International, vol. 27, no. 3, pp. 313-326, April 2011

[10] T. P. Ryan, Statistical Methods for Quality Improvement, $3^{\text {rd }}$ ed., Obokeen, NJ: John Wiley \& Sons, 2011, ch. 10, pp. 356-359.

[11] F. S. Hillier, "X-bar and R-chart control limits based on a small number of subgroups," Journal of Quality Technology, vol. 1, no. 1, pp. 17-26, January 1969.
[12] C. H. Yang and F. S. Hillier, "Mean and variance control chart limits based on a small number of subgroups", Journal of Quality Technology, vol. 2, no. 1, pp. 9-16, January 1970.

[13] M. E. Elam and K. E. Case, "A computer program to calculate two-stage short-run control chart factors for (X-bar, R) charts," Quality Engineering, vol. 14, no. 1, pp. 77-102, 2001.

[14] M. E. Elam, and K. E. Case, "A computer program to calculate two-stage short-run control charts for (Xbar, $v$ ) and (Xbar, $\sqrt{v}$ ) charts," Quality Engineering, vol. 15, no. 4, pp. 609-638, 2003.

[15] M. E. Elam and K. E. Case, "A computer program to calculate two-stage short-run control chart factors for (Xbar, s) charts," Quality Engineering, vol. 17, no. 2, pp. 259-277, 2005.

[16] M. E. Elam and K. E. Case, "Two-stage short-run (Xbar, v) and (Xbar, $\sqrt{v}$ ) control charts," Quality Engineering, vol. 15, no. 3, pp. 441-448, 2003.

[17] M. E. Elam and K. E. Case, "Two-stage short-run (Xbar, s) control charts," Quality Engineering, vol. 17, no. 1, pp. 95-107, 2004.

[18] M. E. Elam and K. E. Case, "Two-stage short-run (X, MR) control charts," Journal of Modern Applied Statistical Methods, vol. 7, no. 1, pp. 95-107, May 2008.

[19] C. P. Quesenberry, "SPC Q Charts for start-up processes and short or long runs," Journal of Quality Technology, vol. 23, no. 3, pp. 213-224, July 1991

[20] C. Zou et al., "A spatial rank-based multivariate EWMA control chart," Naval Research Logistics, vol. 59, no. 2, pp. 91-82, March 2012.

[21] C. P. Quesenberry, "SPC Q charts for a binomial parameter $p$ : short or long runs," Journal of Quality Technology, vol. 23, no. 3, pp. 213-224, July 1991.

[22] C. P. Quesenberry, "SPC Q charts for a poisson parameter $\lambda$ : short or long runs," Journal of Quality Technology, vol. 23, no. 4, pp. 239-246, October 1991.

[23] Z. Li, Y. Luo, and Z. Wang, "CUSUM of Q chart with variable sampling intervals for monitoring the process mean," International Journal of Production Research, vol. 48, no. 16, pp. 5861-4876, 2010.

[24] Z. Li and Z. Wang, "Adaptive CUSUM of Q chart," International Journal of Production Research, vol. 48, no. 5, pp. 1287-1301, 2010.

[25] H. Kawamura, K. Nishina, M. Higashide, and T. Suzuki, "Application of Q charts for short run autocorrelated data," International Journal of Innovative Computing, Information and Control, vol. 9, no. 9, pp. 3667-3676, September 2013

[26] D. M. Hawkins, "Self-starting CUSUM charts for location and scale," Journal of the Royal Statistical Society. Series D (The Statistician), vol. 36, no. 4, pp. 299- 316, 1987.

[27] A. J. Koning and R. J. Does "CUSUM Charts for Preliminary Analysis of Individual Observations," Journal of Quality Technology, vol. 32, no. 2, pp. 122-132, 2000

[28] D. R. Bothe, SPC for Short Production Runs, Northville, MI International Quality Institute, 1988, ch. 2 \& 3, pp. 2-33.

[29] D. Wheeler, Short Run SPC, Knoxville, TN, 1991, ch. 3, pp.11-16.

[30] L. Zhang, G. Chen, and P. Castagliola, "On t and EWMA t charts for monitoring changes in the process mean," Quality and Reliability Engineering International, vol. 25, no. 8, pp. 933-945, March 2009.

[31] P. Castagliola, G. Celano, S. Fichera, and G, Nenes, "The variable sample size t control chart for monitoring short production runs," International Journal on Advanced Manufacturing Technology, vol. 66, pp. 1353-1366, June 2013.

[32] M. E. Calzada and S. M. Scariano, "The synthetic t and synthetic EWMA t charts," Quality Technology \& Quantitative Management, vol. 10, no. 1, pp. 37-56, March 2013.

[33] D. M. Hawkins, P. Qiu, and C. W. Kang, "The change point model for statistical process control," Journal of Quality Technology, vol. 35, no. 4, pp. 355-366, October 2003.

[34] D. M. Hawkins and K. D. Zamba. "A change point model for a shift in variance," Journal of Quality Technology, vol. 37, no. 1, pp. 21-31, January 2005.

[35] D. M. Hawkins and K. D. Zamba, "Statistical process control for shifts in mean or variance using a change point formulation," Technometrics, vol. 47, no. 2, pp. 164-172, May 2005.

[36] K. D. Zamba and D. M. Hawkins, "A multivariate change point model for statistical process control," Technometrics, vol. 48, no. 4, pp. 539-549, 2006.

[37] M. B. Khoo and H. L. Gan, "An improved multivariate short-run control chart based on the CUSUM statistic," in Proc. 1st IMT-GT Regional Conference on Mathematics Statistics and Their Applications, 2005, pp. 287-292.

[38] L. Jaupi, D. E. Herwindiati, P, Durant, and D. Ghorbanzadeh, "Short-run multivariate control charts for process mean and variability," in Proc. World Congress on Engineering, 2013, pp. 1-5. 
[39] V. Makis, "Multivariate bayesian process control for a finite production run," European Journal of Operational Research, vol. 194, no. 3, pp. 795-806, May 2009.

[40] A. Snoussi, "SPC for short-run multivariate autocorrelated processes," Journal of Applied Statistics, vol. 38, no. 10, pp. 2303-2312, Jan. 2011

[41] A. Snoussi, M. E. Ghourabi, and M. Limam, "On SPC for short run autocorrelated data," Communications in Statistics - Simulation and Computation, vol. 34, no. 10, pp. 219-234, 2005.

[42] A. Snoussi and M. Limam, "The change point model: SPC method for short run autocorrelated data," Quality Technology \& Quantitative Management, vol. 4, no. 3, pp. 313-329, September 2007.

[43] C. M. Wright, D. E. Booth, and M Y, Hu, "Joint estimation: SPC method for short-run autocorrelated data," Journal of Quality Technology, vol. 33, no. 3, pp. 365-377, July 2001.

[44] B. Wu and J. Yu, "A neural network ensemble model for on-line monitoring of process mean and variance shifts in correlated processes,' Expert Systems with Applications, vol. 37, no. 6, pp. 4058-4065, 2010

[45] P. Tsiamyrtzis and D. M. Hawkins, "A bayesian EWMA method to detect jumps at the start-up phase of a process," Quality and Reliability Engineering International, vol. 24, no. 6, pp. 721-735, August 2008.

[46] C. Zhou, C. Zou, Y. Zhang, and Z. Wang. "Nonparametric control chart based on change-point model," Statistical Papers. vol. 50, no. 1, pp. 13-28, January 2009.

[47] C. Zou and F. Tsung, "Likelihood ratio-based distribution-free EWMA control charts," Journal of Quality Technology, vol. 42, no. 2, pp. 174-196, April 2010.

[48] R. Guo and T. Dunne, "Grey predictive process control charts," Communications in Statistics - Theory and Methods, vol. 35, no. 10, pp. 1857-1868, November 2006

[49] M. Aminnayeri, E. A. Torkamani, M. Davodi, and M. Ramtin, "Short-run process control based on non-conformity degree," in Proc. World Congress in Engineering, 2010, vol. 3, London, UK, pp. 2273-2276.

[50] C. P. Quesenberry, "On properties of binomial Q-charts for attributes," Journal of Quality Technology, vol. 27, no. 3, pp. 204-213, July 1995.

[51] C. P. Quesenberry, "Geometric Q charts for high quality processes," Journal of Quality Technology, vol. 27, no. 4, pp. 304-315, Oct. 1995.

[52] D. J. Fonseca, M. E. Elam, and L. Tibbs, "Fuzzy short-run control charts," Mathware \& Soft Computing, vol. 14, no. 2, pp. 81-101, 2007.

[53] C. P. Quesenberry, "On properties of poisson Q-charts for attributes," Journal of Quality Technology, vol. 27, no. 4, pp. 293-303, Oct. 1995.

[54] G. Nedumaran and. J. V. Leon, "p-chart control limits based on a small number of subgroups," Quality Engineering, vol. 11, no. 1, pp. 1-9, September 1998.

[55] C. P. Quesenberry, "The multivariate short-run snapshot Q chart," Quality Engineering, vol. 13, no. 4, pp. 679-683, June 2001.

[56] M. Khoo and S. Quah, "Proposed short runs multivariate control charts for the process mean," Quality Engineering, vol. 14, no. 2, pp. 603-621, 2002.

[57] S. V. Crowder and L. Eshleman, "Small sample properties of an adaptive filter applied to low volume SPC," Journal of Quality Technology, vol. 33, no. 1, pp. 29-46, January 2000.

[58] C. M. Wright, "A note on the joint estimation method for short-run autocorrelated data," Communications in Statistics - Simulation and Computation, vol. 32, no. 4, pp. 1105-1114, 2003.

[59] C. P. Quesenberry, "On properties of Q-Charts for variables," Journal of Quality Technology, vol. 27, no. 3, pp. 184-203, July 1995.

[60] V. E. Sower, J. G. Motwani, and M. J. Savoie, " $\delta$ charts for short run statistical process control," International Journal of Quality \& Reliability Management vol. 11, no. 6, pp. 50-56, 1994.

[61] M. Garjani, R. Noorossana, and A. Saghaci, "A neural network-based control scheme for monitoring start-up processes and short runs," International Journal of Advanced Manufacturing Technology, vol. 51, no. 9-12, pp. 1023-1032, December 2010.

[62] J. G. Requeijo. "Técnicas avançadas do controlo estatístico do processo," (Advanced techniques of statistical process control), Ph.D dissertation (in Portuguese), Faculty of Science and Technology, NOVA University of Lisbon, Lisbon, Portugal, 2003.

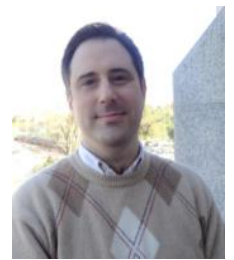

Pedro A. Marques was born in Lisbon, in February 1978. He obtained the diploma in 2001 and Ph.D. in 2013 in industrial engineering from the NOVA University of Lisbon, Portugal. Certified Six Sigma Black Belt by ASQ.

He was a senior consultant with ISQ (2006-) in Portugal. He was also a researcher in 2012 in this institution. He was a guest lecturer at the Catholic University of Portugal from 2008 to 2012 . He was an invited researcher at the Research and Development Unit for Mechanical and Industrial Engineering from 2007 to 2012. He has been lecturing Six Sigma, as guest speaker, at ISCTE Lisbon University Institute, NOVA University of Lisbon, UFMG (Brazil), and UFOP (Brazil)

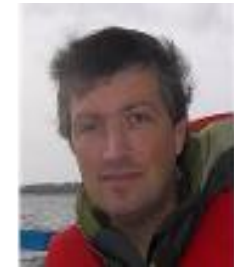

Carlos B. Cardeira was born in Quinjenje, Angola, and received the engineering and master of science degrees in 1986 and 1991, in electrical engineering from Instituto Superior Técnico in Lisbon - Portugal In 1994 he received the $\mathrm{PhD}$ in electrical engineering and computer science from the Institut National Polytechnique de Lorraine in Nancy - France.

$\mathrm{He}$ is a member of the Center of Intelligent Systems of the IDMEC research laboratory and teaches at Instituto Superior Técnico in Lisbon courses in Industrial Automation and Informatics areas. He made several post-docs and sabbatical leaves, namely in IRIT and LAAS in Toulouse - France, CERN in Geneva - Switzerland and Schneider-Electric in Seligenstadt - Germany.

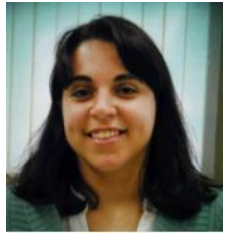

Paula Paranhos was born in Oporto, in June of 1977 She obtained the diploma in chemical engineering from the ISEP Engineering Polytechnic Institute in 2001, in Portugal. She received the post-graduate degree in occupational health \& safety from Instituto de Seguros, in Portugal.

She is a director of quality at IDEPA - Indústria de Passamanarias, Lda., being also in charge of the Environmental and Occupational Health \& Safety management systems.

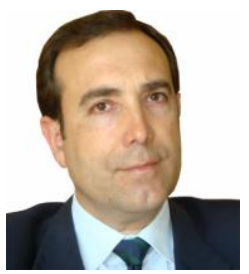

Sousa Ribeiro was born in Marco de Canaveses, in 1965. He obtained the diploma in informatics from the Portucalense University in 1990; post-graduate degree in marketing and international Trading from ISEP Engineering Polytechnic Institute; MSc in informatics engineering from the University of Oporto (FEUP) in 2004

He is the founder and CEO of SisTrade - Software Consulting S.A., in Portugal. He is also a lecturer at the ISEP Engineering Polytechnic Institute, in Oporto, since 1991. He held the position of marketing \& sales manager at EFACEC, in Portugal.

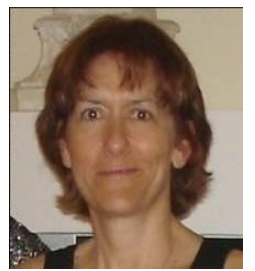

Helena Gouveia was born in Lisbon, in October 1956. She obtained the diploma in metallurgical engineering from the IST - Technical University of Lisbon, in Portugal in 1980; Ph.D. in laser welding from the Cranfield University, in England, UK (1994).

She is currently the head of the Business Development Unit at ISQ. She is a senior researcher in the fields of materials and production technologies, being responsible for the coordination of several national and European research projects. She has several papers and communications in scientific meetings. 